\title{
Treatment of coronary chronic total occlusion by transradial approach: Current trends and expert recommendations
}

\author{
Leszek Bryniarski ${ }^{1}$, Michał Zabojszcz ${ }^{2}$, Krzysztof L. Bryniarski ${ }^{3}$ \\ ${ }^{1} 1^{\text {st }}$ Department of Cardiology Interventional Electrocardiology and Arterial Hypertension, \\ Cardiology Institute, Jagiellonian University Medical College, University Hospital, Krakow, Poland \\ ${ }^{2}$ Department of Cardiology, Dietl's Hospital, Krakow, Poland \\ ${ }^{3}$ Department of Interventional Cardiology, Cardiology Institute, \\ Jagiellonian University Medical College, John Paul II Hospital, Krakow, Poland
}

\begin{abstract}
The aim of this review is to highlight the technical details and the scientific data on percutaneous coronary interventions (PCIs) in chronic total occlusion (CTO) performed by transradial approach (TRA). Transfemoral approach (TFA) is commonly regarded as the standard for CTO PCI, but there is a growing number of CTO recanalization procedures performed by TRA. We discuss the relevant technical details to approach a CTO by transradial access, especially the compatibility of various CTO recanalization techniques with specific guiding catheter sizes. Randomized prospective trials in this field are lacking and only data from observational studies are available. We can conclude that transradial access for CTO PCI is feasible and could be very useful in selected patients. In our opinion, transradial access in CTO PCIs should be limited to operators and centers highly experienced in CTO recanalization and in TRA. (Cardiol J 2017; 24, 6: 695-699)
\end{abstract}

Key words: chronic total occlusion, transradial approach, transfemoral approach, percutaneous coronary intervention

\section{Introduction}

Percutaneous coronary interventions (PCIs) in chronic total occlusion (CTO) still represent one of the hardest procedures in interventional cardiology. It requires very careful preparation including: evaluation of clinical situation, assessment of left ventricular function, ischemia and viability, analysis of the angiogram and planning of the procedure. One of the elements of procedure plan is selection of arterial access. Routine practice of the majority of CTO-dedicated centers and operators shows that CTO PCIs are performed mainly using large guiding catheter and transfemoral approach (TFA). The TFA is the worldwide accepted method for CTO intervention as femoral artery can accommodate a larger guiding catheter providing better support and a larger working space. Nevertheless, TFA has several clinical and anatomical limitations including distal abdominal aortic disease, very tortuous or occluded ilio-femoral arteries, morbid obesity, and long period of bed rest required after the procedure.

Transfemoral access is associated with higher risk of vascular access complications [1]. Significant hemostatic difficulties can occur with the TFA in obese patients, which may increase the risk of groin complications and lead to longer hospitalization. The risk reduction is more pronounced among patients presenting with acute coronary syndromes, likely because of aggressive antico-

Address for correspondence: Leszek Bryniarski, MD, PhD, FESC, $1^{\text {st }}$ Department of Cardiology, Interventional Electrocardiology, and Arterial Hypertension, University Hospital, Jagiellonian University Medical College, ul. Kopernika 17, 31-501 Kraków, Poland, tel: +48 1242473 00, fax: +48 1242473 20, e-mail: 1_bryniarski@poczta.fm 
agulation and antiplatelet regimens used in these patients [1].

An alternative approach for CTO interventions is therefore needed to addresses these limitations.

The data from the literature as well as clinical practice indicate that transradial approach (TRA) is a valuable alternative to TFA. It has been reported that using TRA reduces vascular complications and may be associated with a better clinical outcome. For these reasons, radial access is widely used in routine coronary procedures, and is recommended especially in acute coronary syndromes [2]. Transradial access is also used in complex percutaneous coronary intervention (PCI) and peripheral interventions. There is a growing body of evidence regarding the use of this approach also in CTO procedures [3].

The TRA for PCI was introduced in 1993, and has been shown to have many benefits as compared with the TFA, such as: fewer access site complications, earlier ambulation, shorter hospital stay, patient preference and lower medical cost. The popularity of the TRA for PCI varies by country, and although a longer learning curve of TRA has been reported, in places such as Canada, Europe, and Asian regions, the TRA for PCI comprise from $40 \%$ to $60 \%$ of all PCI cases [4]. In 2015 in Poland most coronary angiographies $(80 \%)$ were performed via TRA (unpublished data of Polish Registry of Invasive Cardiology Procedures). Polish data regarding usage of TRA in CTO are limited. Jaguszewski et al. [5] in a series of 1110 CTO treated by antegrade approach from 2003 to 2010 reported no differences in success rate depending on the chosen access site. As described in the first Polish publication concerning recanalization of coronary chronic total occlusion by retrograde approach, in this special sub-set of procedures we used only femoral access [6].

In this review, we provide an overview of technical details of TRA for CTO PCI and existing scientific data in this field.

\section{Technical aspects}

In the EuroCTO Club consensus document prepared by the top European experts in the field of CTO recanalization, the authors emphasize that in Europe most experts use the femoral approach for the target CTO vessel (90\%). Moreover, they state that it has not been shown that either access is preferable except for about $10 \%$ of the cases in which even experienced radial operators select the femoral route $[7,8]$. Surprisingly, the same statement was published 5 years earlier in the first EuroCTO Club consensus [9].

The selection of the access route is determined by the individual patient's situation. Operator may be forced to use TRA in severe peripheral vascular disease or when only one femoral access is available to use in combined approach, femoral and radial. In this specific situation femoral approach is used for CTO lesion, and the radial for contralateral injection (5 Fr or 6 Fr diagnostic catheters) or for retrograde access in retrograde procedure. Operator's preferences and familiarity with both accesses are very important.

The first step for a successful CTO recanalization is the selection of the guiding catheter. Correct guiding catheter should provide the necessary back-up force, support and stability throughout the whole procedure. Obtaining good passive support with coaxial alignment or ability to introduce guiding catheter into the coronary artery for active support is crucial for CTO procedures [7]. Passive support is greatest with large guiding catheters such as 7 Fr or 8 Fr, while 6 Fr catheters offer the best balance between active and passive support. In the authors' opinion, it is more difficult to obtain good support by TRA.

The catheter shape is essential for providing optimal engagement of the artery and a coaxial orientation. The extra back-up shape is the most used for the left coronary engagement, especially if a TRA is planned. Amplatz left curves are good alternatives, mostly for left circumflex lesions. For the right coronary artery, Judkins right or Amplatz right represent the best choice, while the Amplatz left curves are useful for shepherd's crook origin engagement.

Selection of the right catheter size should be dictated by the type and combination of devices used during the procedure. It should be noted that bigger catheters provide higher passive back-up. However, modern interventional cardiology is moving away from the use of large catheters, mainly due to the miniaturization of intracoronary balloons and stents. On the contrary, procedures of CTO recanalization are very complex, and it is not so rare that the combination of dedicated microcatheters, intravascular ultrasound, re-entry devices and bilateral injection has to be utilized.

Despite optimal catheter selection and coronary engagement, sometimes an extra back-up support is needed. If a small catheter is selected, extra support may be achieved by deeper intubation. Otherwise anchoring the catheter to a small branch may be second option. 
As the alternative, a mother and child device or catheter extension can be employed. Of note, in very proximal and ostial lesions or in small coronaries, if a strong dye injection is performed, the catheter engagement may cause pressure damping or vessel dissection. To avoid these events, guiding catheters with side holes are often indispensable, especially if a $7 \mathrm{Fr}$ or $8 \mathrm{Fr}$ catheter is selected.

Ghione et al. [10] tested in vitro $5 \mathrm{Fr}, 6 \mathrm{Fr}, 7 \mathrm{Fr}$ and 8 Fr guiding catheters (Launcher; Medtronic Inc., Minneapolis, MN, USA) and $6 \mathrm{Fr}$ and $7 \mathrm{Fr}$ GuideLiner $^{\circledR}$ (Vascular Solutions, Minneapolis, MN, USA) with frequently employed devices for CTO recanalization such as new-generation over-thewire (OTW) and monorail balloons, microcatheters, dedicated devices and intravascular ultrasound (IVUS) probes. In 6 Fr guiding catheters, all the dedicated CTO devices can be inserted alone. Only two end-hole support microcatheters or one microcatheter and a monorail balloon fit together. In $7 \mathrm{Fr}$ guiding catheters, many more devices can be used in a combination, including two Corsair microcatheters (Asahi Intecc, Aichi, Japan) and three smaller devices such as two Finecross ${ }^{\circledR} \mathrm{MG}$ microcatheters (Terumo Europe, Leuven, Belgium) and/or Valet microcatheter (Volcano, San Diego, CA, USA) and a monorail anchoring balloon. An $8 \mathrm{Fr}$ guiding catheter provides sufficient space for inserting all the devices and the IVUS probe (Eagle Eye, Volcano, San Diego, CA, USA), including the Venture $^{\circledR}$ catheter (St. Jude Medical, Inc., St. Paul, MN, USA), as well as a wider array of two and three devices in combination. It is also possible in an $8 \mathrm{Fr}$ catheter to use a combination of Stingray ${ }^{\circledR}$ coronary CTO re-entry system (BridgePoint/Boston Scientific, Natick, MA, USA) and 1.25 OTW balloon.

Burzotta et al. [3] performed the bench test and described in details compatibility of CTO PCI techniques that could be currently used with different guiding catheters (GC). The internal diameters of GC from different companies (Cordis, Medtronic and Asahi) vary from $0.56-0.58$ inch for 5 Fr guiding catheters to $0.88-0.90$ inch for $8 \mathrm{Fr}$ guiding catheters [3]. The authors divided access device sizes into following categories: $5 \mathrm{Fr}$ sheath + GC, 6 Fr sheath + GC, 6.5 Fr sheathless GC, 7 Fr sheath + GC, 7.5 Fr sheathless GC, and 8 Fr sheath + GC. They tested Finecross (Terumo) and Quickross (Spectranetics) microcatheters, but not very popular currently Corsair microcatheter (Asahi). Possible combinations for the parallel wire technique include: wire +1 microcatheter (can be used in every situation), 2 microcatheters (not in 5 Fr GC), 1 microcatheter +1 OTW balloon (in
7 Fr GCs and larger), 2 OTW balloons (only in 8 Fr GC). Side branch anchoring balloon and balloon trapping (useful for both antegrade and retrograde PCI technique) with the use of 1 monorail balloon +1 microcatheter or 1 monorail balloon +1 OTW balloon demand GC larger than $5 \mathrm{Fr}$.

When performing CTO PCI under IVUS guidance (which is increasingly popular technique) using a wire supported by microcatheter, the size of GC must be at least $7 \mathrm{Fr}$.

In CTO recanalization there are many adjunctive devices useful for both antegrade and retrograde CTO PCI techniques. Rotablation is a unique technique that can help in dilatation of heavily calcified vessels. When using rotablator with $1.25-1.75 \mathrm{~mm}$ burr, minimal size of GC is 6.5 Fr sheathless, and for rotablator with $2.0-2.25 \mathrm{~mm}$ burr minimal size is 7 Fr GC. Laser 0.9-1.4 mm could be accommodated by smallest GC; for laser 1.7-2.2 mm minimal size of $\mathrm{GC}$ is $7 \mathrm{Fr}$. For both diameters of Tornus, $2.1 \mathrm{Fr}$ and $2.6 \mathrm{Fr}$, required size of the catheter is minimum $6 \mathrm{Fr}$ GC. Corsair (Asahi) microcatheter could be accommodated by 6 Fr GC, but based on our experience, a catheter of this size does not provide sufficient space to introduce other devices and if the use of other devices is planned, a minimum size of a GC is $7 \mathrm{Fr} \mathrm{GC}$. For CrossBoss Catheter and Stingray CTO re-entry device 6 Fr GC could be used, but to allow the other techniques to be utilized larger GC is necessary.

The manufacturers work constantly on miniaturizing the external diameter of the guiding catheters and providing larger internal diameter; therefore, there is a growing need for obtaining the results of the new bench tests of new guiding catheters.

We should stress some limitations of the bilateral forearm approach. Firstly, the forearm arteries have potential anatomical variations such as looping or small accessory radial arteries. Moreover, buckling of the innominate artery can occur or tortuosity of the subclavian artery may be present. Secondly, patients with end-stage renal disease may need further protection of the forearm arteries. Finally, the retrograde shorter guiding catheter $(85-90 \mathrm{~cm})$ is too short to reach the coronary ostia in patients who are taller than $175 \mathrm{~cm}$.

There are also some tips and tricks that allow simultaneous usage of two 6 Fr guiding catheters, one as an operating guidewire and the other for retrograde visualization and for antegrade IVUS control, using so called "ping-pong technique" [11]. Nowadays, use of a sheathless guiding system allows CTO PCI with 8.5 Fr guiding catheters introduced through an arterial puncture equivalent to 
that created by a 6 Fr sheath, obviating some of the challenges associated with small radial sheath size.

The equipment for PCI is being miniaturized year by year. This can lead to improvement of TRA CTO interventions by increasing the number of techniques which can be performed through small sheaths. Moreover, new smaller guiding catheters with sufficient internal lumen to perform complex CTO procedure are being developed [2].

\section{Scientific data}

There are many studies in the available literature but none of them is randomized. In 2013 Burzotta et al. [3] published a meta-analysis concerning $\mathrm{PCI}$ on CTO by radial approach. They performed a systematic search both in Medline and in the main international websites. Key data were extracted and analyzed using standard meta-analytic techniques. They identified 13 observational studies including 3501 CTOs treated by TRA. Overall, the crossover to TFA rate ranged between $0 \%$ and $5.8 \%$. Access site complications were noted in $<1 \%$ of cases and in-hospital major adverse events were reported in $0-3.8 \%$ of patients. PCI success was significantly influenced by the learning curve: in 5 studies a significant improvement in the success rate between the initial and later period of practice was observed (OR $0.30,95 \%$ CI $0.39-0.51 ; \mathrm{p}<0.001)$. In cited publication, the main technique used for recanalization was antegrade technique with procedure success varying from $66 \%$ to $84 \%$. In 3 biggest reported series of patients by Wu et al. (909 patients), Yang et al. (400 patients) and Ferrante et al. (848 patients), success rate was relatively low (from $77 \%, 69 \%$ and $73 \%$, respectively) [12-14]. Retrograde technique was used by Burzotta et al. [15] in 3\% of 167 lesions and by Liu et al. [16] in $5.8 \%$ of 120 lesions, which is lower than actually reported frequency of usage of this very important technique [6]. Two papers describe the patients treated only retrogradely, $\mathrm{Wu}$ et al. [4] and Rinfret et al. [17] reported $87 \%$ and $88 \%$ success rate, respectively. We do not have the possibility to assess the difficulty of attempted lesions as the J-CTO score which is the most popular index of severity of CTO was not available at the time of majority of those publications, or not calculated nor reported.

Recently, American authors presented their experience comparing the technique and outcome of TRA vs. TFA access among 650 CTO PCI cases performed between January 2012 and March 2014 at 6 United States centers [18]. TRA access was used in 110 (17\%) of the 650 cases. They used bilateral radial access (63\%), bilateral radial access plus unilateral or bilateral femoral access (7\%), unilateral radial access plus unilateral or bilateral femoral access $(26 \%)$, and unilateral radial access $(4 \%)$. Similar technical (92.6\% vs. $93.0 \%, \mathrm{p}=0.87)$ and procedural $(91.1 \%$ vs. $90.0 \%, \mathrm{p}=0.95)$ success and major complication rates $(1.7 \%$ vs. $1.8 \%, \mathrm{p}=0.99)$ were observed. However, TRA access was associated with higher mean procedure duration $(142 \pm 83$ vs. $120 \pm 60 \mathrm{~min}, \mathrm{p}=0.008)$, fluoroscopy time ( $58 \pm 40$ vs. $49 \pm 31 \mathrm{~min}, \mathrm{p}<0.026)$ and number of crossing approach changes $(0.7 \pm 1.0$ vs. $0.5 \pm 0.7$, $\mathrm{p}=0.008)$. They also calculated J-CTO score: in all group it was $2.7 \pm 1.2$ and in TRA group it was significantly higher $(3.1 \pm 1.0)$ compared with $2.6 \pm 1.2$ in TFA group $(\mathrm{p}<0.001)$. Looking at the technical aspects of the procedures, the final successful crossing technique with TRA was more commonly antegrade wire escalation ( $57 \%$ vs. $39 \%$ ) and less commonly antegrade dissection re-entry ( $17 \%$ vs. $29 \%$ ), whereas use of the retrograde approach was similar in both groups ( $27 \%$ vs. $32 \%$ ).

It should be emphasized that most patients included in those studies were men. Although women are more likely than men to have vascular access complications with a TFA, they also have smaller radial arteries, which may preclude utilization of large catheters [19, 20]. We should also remember that cited studies were performed by highly experienced operators in experienced centers and the results cannot be automatically translated into real world. A meta-analysis of Burzotta et al. [3] showed significant improvement in the transradial CTO PCI success rates with increasing experience. Of particular importance is proper education of interventional cardiologists and dedicated CTO operators $[7,21]$. Therefore, the potential benefits of the TRA (lower risk for vascular access complications) should be weighed against the potential disadvantages of this approach and the decision to proceed with either approach should be based on the characteristics of the individual patient as well as the operator's experience.

\section{Conclusions}

Transradial access for coronary CTO treatment is feasible and could be very useful in selected patients and clinical situations. In our opinion, TFA still remains the gold standard for PCI in CTO, especially in complex lesions and retrograde 
techniques. Routine TRA should be limited to operators and centers highly experienced in CTO recanalization and in transradial approach.

\section{Conflict of interest: None declared}

\section{References}

1. Jolly S, Yusuf S, Cairns J, et al. Radial versus femoral access for coronary angiography and intervention in patients with acute coronary syndromes (RIVAL): a randomised, parallel group, multicentre trial. The Lancet. 2011; 377(9775): 1409-1420, doi: 10.1016/s0140-6736(11)60404-2.

2. Roffi M, Patrono C, Collet JP, et al. Authors, Management of Acute Coronary Syndromes in Patients Presenting without Persistent ST-Segment Elevation of the European Society of Cardiology. 2015 ESC Guidelines for the management of acute coronary syndromes in patients presenting without persistent ST-segment elevation: Task Force for the Management of Acute Coronary Syndromes in Patients Presenting without Persistent ST-Segment Elevation of the European Society of Cardiology (ESC). Eur Heart J. 2016; 37(3): 267-315, doi: 10.1093/eurheartj/ ehv320, indexed in Pubmed: 26320110.

3. Burzotta F, De Vita M, Lefevre T, et al. Radial approach for percutaneous coronary interventions on chronic total occlusions: technical issues and data review. Catheter Cardiovasc Interv. 2014; 83(1): 47-57, doi: 10.1002/ccd.25118, indexed in Pubmed: 23832527 .

4. Wu CJ, Fang HY, Cheng CI, et al. The safety and feasibility of bilateral radial approach in chronic total occlusion percutaneous coronary intervention. Int Heart J. 2011; 52(3): 131-138, indexed in Pubmed: 21646733.

5. Jaguszewski M, Ciecwierz D, Gilis-Malinowska N, et al. Successful versus unsuccessful antegrade recanalization of single chronic coronary occlusion: eight-year experience and outcomes by a propensity score ascertainment. Catheter Cardiovasc Interv. 2015; 86(2): E49-E57, doi: 10.1002/ccd.25841, indexed in Pubmed: 25599675.

6. Bryniarski L, Surowiec S, Klima $€$, et al. Recanalisation of coronary chronic total occlusion by retrograde approach: the first experience in Poland. Kardiol Pol. 2015; 73(3): 167-176, doi: 10.5603/KP.a2014.0167, indexed in Pubmed: 25179481.

7. Sianos G, Werner GS, Galassi AR, et al. EuroCTO Club. Recanalisation of chronic total coronary occlusions: 2012 consensus document from the EuroCTO club. EuroIntervention. 2012; 8(1): 139-145, doi: 10.4244/EIJV8I1A21, indexed in Pubmed: 22580257.

8. Galassi AR, Tomasello SD, Reifart N, et al. In-hospital outcomes of percutaneous coronary intervention in patients with chronic total occlusion: insights from the ERCTO (European Registry of Chronic Total Occlusion) registry. EuroIntervention. 2011; 7(4): 472-479, doi: 10.4244/EIJV7I4A77, indexed in Pubmed: 21764666.

9. Di Mario C, Werner GS, Sianos G, et al. European perspective in the recanalisation of Chronic Total Occlusions (CTO): consensus document from the EuroCTO Club. EuroIntervention. 2007; 3(1): 30-43, indexed in Pubmed: 19737682.

10. Ghione M, Agudo P, Kilickesmez K, et al. Tools and techniques clinical: catheter compatibility in CTO recanalisation. EuroIntervention. 2013; 9(2): 290-291, doi: 10.4244/EIJV9I2A46, indexed in Pubmed: 23793014.

11. Nakashima M, Ikari Y, Aoki J, et al. Intravascular ultrasoundguided chronic total occlusion wiring technique using 6 Fr catheters via bilateral transradial approach. Cardiovasc Interv Ther. 2015; 30(1): 68-71, doi: 10.1007/s12928-014-0251-y, indexed in Pubmed: 24535707.

12. Wu CJ. Feasibility of bilateral radial access antegrade and retrograde approach for CTO lesions: Single center experience. Personal communication. TCT 2008. www.tctmd.com.

13. Ferrante G, Louvard Y, Hayashida K, et al. TCT-445 Radial Versus Femoral Access for Percutaneous Coronary Interventions in Patients With Chronic Total Occlusion. Journal of the American College of Cardiology. 2012; 60(17): B128, doi: 10.1016/j. jacc.2012.08.476.

14. Yang CH, Guo GBF, Chen SM, et al. Feasibility and safety of a transradial approach in intervention for chronic total occlusion of coronary arteries: a single-center experience. Chang Gung Med J. 2010; 33(6): 639-645, indexed in Pubmed: 21199609.

15. Burzotta F, Trani C, Tommasino A, et al. Impact of operator experience and wiring technique on procedural efficacy of trans-radial percutaneous chronic total occlusion recanalization performed by dedicated radialists. Cardiol J. 2013; 20(5): 560-567, doi: 10.5603/ CJ.a2013.0063, indexed in Pubmed: 23799552.

16. Liu W, Wagatsuma K, Toda M, et al. Short- and long-term followup of percutaneous coronary intervention for chronic total occlusion through transradial approach: tips for successful procedure from a single-center experience. J Interv Cardiol. 2011; 24(2): 137-143, doi: 10.1111/j.1540-8183.2010.00608.x, indexed in Pubmed: 21223374 .

17. Rinfret S, Joyal D, Nguyen CM, et al. Retrograde recanalization of chronic total occlusions from the transradial approach; early Canadian experience. Catheter Cardiovasc Interv. 2011; 78(3): 366-374, doi: 10.1002/ccd.23140, indexed in Pubmed: 21542106.

18. Alaswad K, Menon RV, Christopoulos G, et al. Transradial approach for coronary chronic total occlusion interventions: Insights from a contemporary multicenter registry. Catheter Cardiovasc Interv. 2015; 85(7): 1123-1129, doi: 10.1002/ccd.25827, indexed in Pubmed: 25640902.

19. Loh YJ, Nakao M, Tan WD, et al. Factors influencing radial artery size. Asian Cardiovasc Thorac Ann. 2007; 15(4): 324-326, doi: 10.1177/021849230701500412, indexed in Pubmed: 17664207.

20. Caputo RP, Tremmel JA, Rao S, et al. Transradial arterial access for coronary and peripheral procedures: executive summary by the Transradial Committee of the SCAI. Catheter Cardiovasc Interv. 2011; 78(6): 823-839, doi: 10.1002/ccd.23052, indexed in Pubmed: 21544927.

21. Bryniarski KL, Zabojszcz M, Dębski G, et al. Knowledge of chronic total occlusion among Polish interventional cardiologists. Advances in Interventional Cardiology. 2015; 2: 89-94, doi: 10.5114/pwki.2015.52280. 